\title{
MAGIA, RELIGIÓN Y MITO. \\ HARRY POTTER BAJO EL SIGNO \\ DE LA POSMODERNIDAD
}

\author{
Domingo Sola Antequera \\ Universidad de La Laguna \\ dsola@ull.edu.es \\ Irene C. Marcos Arteaga \\ Universidad de La Laguna \\ imarcosarteaga@gmail.com
}

\section{Resumen}

De una parte, con este trabajo pretendemos poner en relieve cómo la construcción de las historias de Harry Potter viene modelada bajo los parámetros narratológicos de la literatura posmoderna, de la que J.K. Rowling es un ejemplo esquivo y tardío; mientras que, de otra, reflexionaremos cómo esta forma creativa propone la combinación y reformulación de muchos referentes procedentes de la tradición occidental, tanto religiosa como mitológica y popular, que la autora combina hasta borrar su origen.

Palabras Clave: Harry Potter, literatura posmoderna, J.K. Rowling, mitología, tradición popular, cristianismo.

\section{Abstract}

On the one hand, our aim with this paper is try to analyse how Harry Potter stories were built under postmodern narrative patterns in which J.K. Rowling is a late and elusive example. On the other hand, we reflect on how this creative literature process proposes the combination and reformulation of several references of the Western Culture: religious and mythical, artistic and all those related to popular tradition. All this was taken into account when the books metamorphosed into the successful movie saga.

KeYwORDs: Harry Potter, postmodern narrative patterns, J.K. Rowling, mythology, popular traditions, christianism. 
Todo el pensamiento moderno es permeado por la idea de pensar lo imposible.

Michel Foucault

Los relatos potterianos, tanto dentro de la pantalla como fuera de ella, parecen conformarse a partir de un conglomerado de referentes que han sido mezclados con inteligencia en un gran bowl atractivo y atemporal. Desde esa perspectiva resulta interesante plantearse si J.K. Rowling se ha mostrado en ellos como una autora conscientemente posmoderna o si, al menos, lo son sus historias. Incluso podríamos ir más allá si validásemos su obra como el resultado de mezclar, de manera consciente o inconsciente, los múltiples referentes de los grandes maestros de la literatura fantástica anglosajona.

Podríamos entrar así en un parvo y estéril debate sobre todo ello, pues parece evidente que, en el caso del background mitológico de sus personajes y de la querencia religiosa de sus textos, la posmodernidad es un hecho irrefutable.

No queremos decir con ello que en Rowling se bosqueje una crítica a la modernidad, sino más bien un cuestionamiento del carácter absoluto de ciertos valores, de ciertos temas que podríamos considerar como inmutables, replanteándose la forma en la que estos son utilizados.

Es cierto que las diferentes historias del mago de Privet Drive son reflejo de la crisis del pensamiento metafísico moderno, dando cabida a múltiples metarrelatos que pivotan sobre la diversidad, la relativización de los referentes y la historicidad del propio relato, así como sobre la linealidad de las historias. Son muestra de que hay diferentes formas de narrar, de entender el pasado, de utilizar los referentes y, por tanto, de que existen contradictorias formas del saber para una generación que ha cambiado el rumbo del género desde finales del siglo pasado. En este sentido, Rowling, especialmente, relativiza el lenguaje, los símbolos e incluso la lógica en la manera de plantear los episodios de su mundo mágico.

Gianni Vattimo aparece en el horizonte de todo ello cuando habla de la posmodernidad como ese periodo en el que todo vale, donde no hay una sola verdad, ni un único punto de vista, pues el pensamiento dogmático aparece totalmente debilitado. Es así como el lenguaje funciona cual creador de significados y, por ende, de la realidad, en un universo de constantes contradicciones, como indica Monteleone (2002):

Es interesante constatar-así- que, en el mundo de Harry Potter, al igual que en el de Tolkien, los valores humanos están siempre presentes (aunque la intencionalidad de la obra no sea didáctica): las aventuras de este héroe se mueven siempre en coordenadas de lucha entre el bien y el mal. Harry Potter enfrenta constantemente situaciones en las que la moral se hace evidente: no existen buenos y malos predeterminados, sino que el bien y el mal se expresan en el mundo como consecuencia de las decisiones de individuos que ceden o no a sus pasiones; o que son coherentes o no con sus anhelos más elevados y nobles. De modo que la línea divisoria entre el bien y el mal no está trazada en el mundo, sino en medio del corazón del hombre como una especie de Jekyll y Hyde a la vez. 
Desde este punto de vista, las estrategias metaficcionales proponen un tipo de relación diferente con el lector. Estas afectan no solo a la trama sino a la construcción de los personajes, a la estructura del relato, a las relaciones temporales e incluso a la lógica causal; y en el caso de la literatura de Rowling, son especialmente interesantes todas las referencias y alusiones intertextuales que encontramos en la saga del joven mago.

En el caso de las novelas es muy evidente la estructura cíclica de los relatos. Harry arranca sus historias en casa de sus tíos Vernon y Petunia Dursley, a donde vuelve al final de las mismas. Este recurso es habitual en muchos otros textos que pivotan sobre la figura del héroe -desde el Odiseo de Homero en adelante-. Es una elección que genera familiaridad y facilita la incursión en el mundo mágico, así como el regreso al muggle ${ }^{1}$, en un intervalo fantástico donde la resolución de las tramas propone la alteración de los conceptos tradicionales sobre el bien y el mal, sobre lo correcto e incorrecto, y sobre los límites de la cordura y la certidumbre. Paradojas en unos relatos que requieren de una conexión con los lectores cuya voluntad queda suspendida pues, como diría Rowling, «no hay cosa menos atractiva que la gente que no puede creer» (Gaffoglio 2000).

De hecho, las frecuentes relaciones hipertextuales en sus obras proponen «un lector más activo, uno que no solo selecciona su recorrido de lectura, sino que tiene la oportunidad de leer como un escritor; es decir, en cualquier momento, la persona que lee puede asumir la función de autor y añadir enlaces $u$ otros textos al que está leyendo" (Landow 2009). Obviamente hablamos desde un punto de vista metafórico gracias a un universo que la autora propone en continua expansión, en gran parte debido a las informaciones en paralelo que viene ofreciendo desde la interacción digital en Pottermore, actualmente reconvertida en Wizardingworld. Esta manifestación intertextual facilita, además, posibles hibridaciones y nuevas formas de lectura, de acercamientos a la obra, así como al fenómeno.

Es así como a pesar de que hablemos de unas novelas, de unas películas, que hace más de una década que abandonaron las pantallas, parecen encontrarse en permanente transformación, en una suerte de obra coparticipada y no cerrada, que juega a transformarse en constantes (dis)continuidades.

En palabras de Alfredo Saldaña (2012):

La literatura posmoderna se caracteriza por la ruptura de la linealidad temporal narrativa y la copresentación de espacios heterotópicos; tiempo y espacio son de este modo coordenadas que resultan de la confluencia de diferentes y simultáneos momentos y lugares; y se opta con frecuencia por narraciones multilineales y multisecuenciales.

Elementos todos que se pueden rastrear en la obra de Rowling.

\footnotetext{
${ }^{1}$ Se denomina muggle a la persona que no posee ninguna habilidad mágica. Por tanto, con este término se designa a uno de los grupos humanos que coexisten en el universo potteriano.
} 


\section{CAPAS SOBRE CAPAS}

Independientemente de las cuestiones meramente narrativas que, como hemos visto, evidencian su filiación con la posmodernidad, esta resulta perceptible en otros aspectos de vital importancia en su obra. A.S. Bryatt, en un artículo publicado en 2003 en el New York Times, se refería al universo creado por la autora británica como un «secondary secondary world», en clara alusión a los paralelismos entre las historias del mago y la transformación de sus referentes mitológicos, religiosos, literarios y populares, para crear una realidad nueva que se asume como diferente por los lectores. El mundo de Harry Potter se conforma así en base a la constante reinterpretación de arquetipos, haciendo de este en su experiencia vital una extensión de otros héroes épicos, caso de un Frodo Baggins, de un Gilgamesh o de un Perseo, con los que comparte virtudes, drama y el viaje como experiencia de crecimiento personal: nacimientos complicados, atributos especiales, lucha contra el mal, ingenio, humildad, enfrentamientos que superan lo personal para resultar universales, capacidades sobrehumanas y enemigos sobrenaturales. Constantes que se cumplen en la mayoría de los ejemplos que podemos manejar, en los que el tránsito de sus héroes por la historia, por sus historias, no deja de ser un rito de paso.

Pero no se trata únicamente de la reelaboración de arquetipos de toda índole, sino del uso de estos transidos de/por mitologías ajenas que los alteran y enriquecen a la par que desubican a los lectores y espectadores. Imaginemos por un momento a Nagini, una humana maledictus convertida en serpiente gigante, aliada y horrocrux de lord Voldemort, capaz de poseer cuerpos ajenos y enemiga de Harry, que será destruida por Neville Longbotton gracias a la espada de Godric Griffindor. En un solo ser monstruoso Rowling une a las obvias referencias bíblicas, las sánscritas del nombre y las egipcias relativas a Apofis, una de las fuerzas negativas del Duat, encarnación del caos y del mal que el faraón debía evitar en su experiencia en el más allá. De esta forma, la autora combina referencias miticorreligiosas opuestas y sin relación entre sí para crear un icono perdurable de la cultura pop y de la literatura de fantasía contemporánea que rompe límites espaciotemporales, altera la esfera de lo sagrado, difumina la percepción de las fuentes y se acerca al lector actual creando una obvia empatía gracias a la contemporaneidad del relato y a la desacralización de la propia serpiente.

Los filmes y las novelas juegan con este tipo de disrupciones que alteran pasado y presente, sacro y profano, mágico y muggle. La idea que parece manejar la autora es la de disociar aquellas alusiones de las fuentes de las que proceden para, de esta forma, crear su propia mitología. Una descontextualización evidente que bebe del pasado para hibridar un presente compuesto por múltiples piezas moldeadas a partir de recursos muy diversos, procedentes de lugares y tiempos muy distantes entre sí, y de relatos que parecen partir de creencias similares: de la necesidad del ser humano por dar respuesta a los porqués de su existencia. En el fondo, de manera instintiva, siempre tenemos la misma respuesta a los mismos estímulos y, por tanto, recurrimos a los mismos arquetipos míticos que prefiguran los mismos comportamientos que, como sociedad, anhelamos y/o especialmente valoramos. Como resulta evidente, siguiendo esta máxima, los héroes, sus diferentes arquetipos, siguen casi 

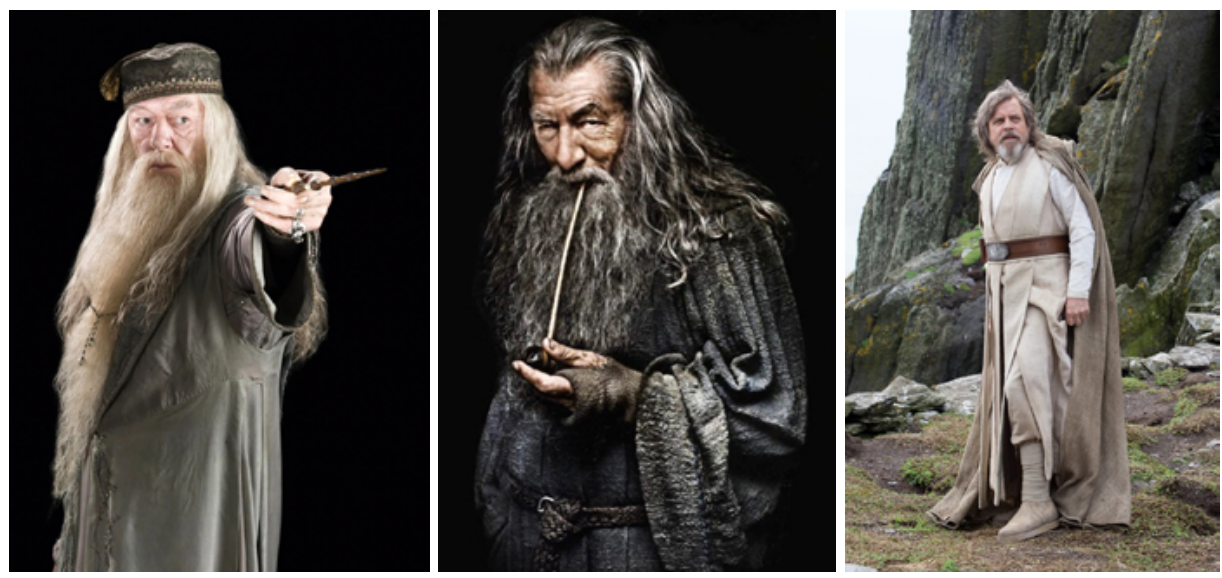

Figs. 1, 2 y 3. Albus Dumbledore, Gandalf el gris, Luke Skywalker.

Imágenes promocionales: HarryPotter.Fandom.com; Spanish Fake Esdla; Starwars.Fandom.com.

siempre los mismos patrones en su elaboración para que podamos reconocerlos sin dificultad alguna puesto que, potencialmente, son imágenes pregnantes per se, una estimulante forma de persuasión.

Este reclamo a las sensibilidades de los lectores más jóvenes no solo se limita a la creación de los seres fantásticos o a la hipertextualidad del relato, sino que incluso podemos rastrearlo en los principales protagonistas de la saga. Quizá el caso más evidente sea el del director de Colegio Hogwarts de Magia y Hechicería, Albus Dumbledore, una mezcla del Merlín de las leyendas artúricas, del Gandalf de los relatos tolkianos sobre la Tierra Media o de dioses nórdicos como Odín.

A primera vista la identificación parece meramente física, semejantes en su apariencia y sabiduría, maestros en la magia; pero si leemos los diferentes relatos de referencia enseguida nos daremos cuenta de que Rowling ha ido algo más allá (Morris n.d.). En Life of Merlin, obra de Geoffrey de Monmouth hacia el año 1150, entre las virtudes de este indica que posee pócimas que permiten el cambio de apariencia de quien las ingiere, exactamente igual que hace Rowling con la denominada poción multijugos, que aparece en diversas ocasiones a lo largo de los filmes. Dumbledore no la ofrece directamente pero, sin duda, maneja los destinos de todos los que le rodean a lo largo de la historia y, por tanto, aboca a su uso. Robert de Boron indica en su poema Merlín que una de sus cualidades es el cambio de apariencia, al igual que lo había hecho el director de Hogwarts antes de ostentar tal cargo. Thomas Malory en La Muerte de Arturo (1485) retrata de nuevo a Merlín como un mago poderoso y soberbio que es capaz de manipular a otros para sus propios fines. Además, lo imagina cubierto por una larga túnica en consonancia con su melena cana. Ambos elementos encajan perfectamente con el Dumbledore de Rowling. Por último, para terminar con estas referencias cruzadas, si este poseía el Espejo de Oesed, que permitía que alguien pudiera ver sus más profundos deseos, 


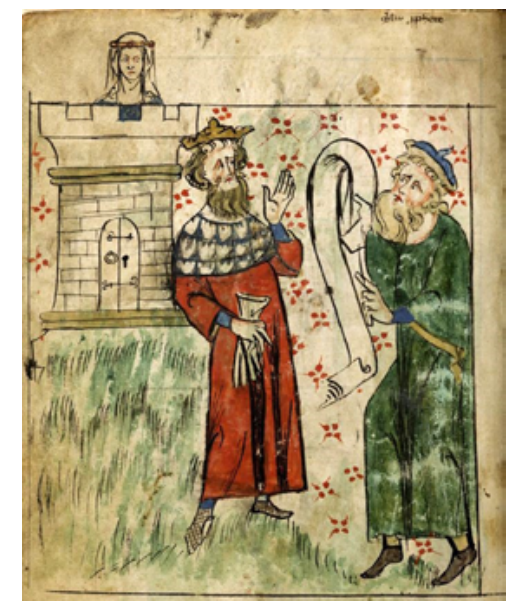

Fig. 4. Rey Uther Pendragon y Merlín. Manuscrito medieval. British Library MS Royal 20.A.II, f. 3v.

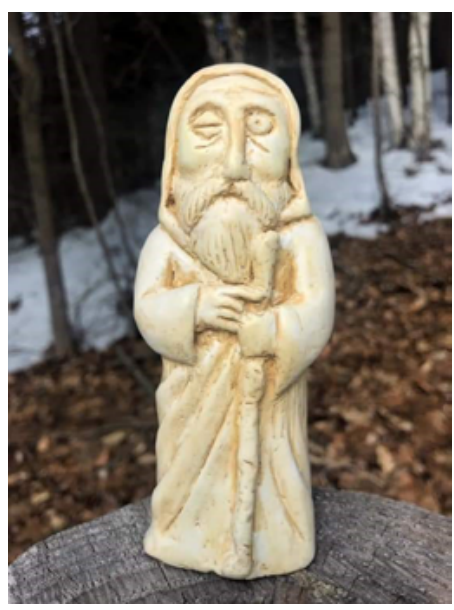

Fig. 5. Odín, el vagabundo. GravenImageStudio.

Merlín, según Edmund Spenser en «La Reina Hada» (1590), poseía el Espejo del Rey Rhyence, que igualmente le permitía ver lo que anhelase. Obviamente nada de ello parece casual, más bien resulta absolutamente intencionado el uso de los referentes de la tradición artúrica en la construcción del personaje.

Que Gandalf nos venga a la mente es, sin duda, la mayor de las obviedades por la necesidad de Rowling de asimilar las enseñanzas de Tolkien, de quien toma la constante lucha entre el bien y el mal como conceptos unívocos e irreconciliables. En ambos este último adquiere corporeidad y se extiende por todo lo creado, y en ambos el bien es bello y verdad, mientras que el mal es falsedad y fealdad, sin duda elementos tomados de los tradicionales cuentos de hadas. De ahí el carácter cristiano y moralizante de su obra, aunque plantee bondad y maldad como términos objetivos y absolutos, al contrario de la autora británica, que los relativiza.

En diversas ocasiones podemos encontrarnos la relación entre ambos escritores, aunque la segunda no tenga la misma consideración como autora y su obra no esté a la altura de la del primero. En palabras de Mark Gauvreau Judge (2000):

La serie de Rowling es un conjunto de cuentos selectos que sirven para que los nińos norteamericanos lleguen a ser un poco más narcisistas de lo que son; y los libros de Tolkien son una obra de arte y, esto es crucial, una tragedia completamente adulta con profundas implicaciones morales y religiosas.

A pesar de estos juicios de valor, que aun siendo ciertos resultan extremos, en ambos casos sus historias parecen tener cierta función pedagógica, ofreciéndonos modelos de comportamiento que funcionan tanto en el pasado como en el presente. Como plantea Ruth A. Robbins (2006), «we understand narrative because 


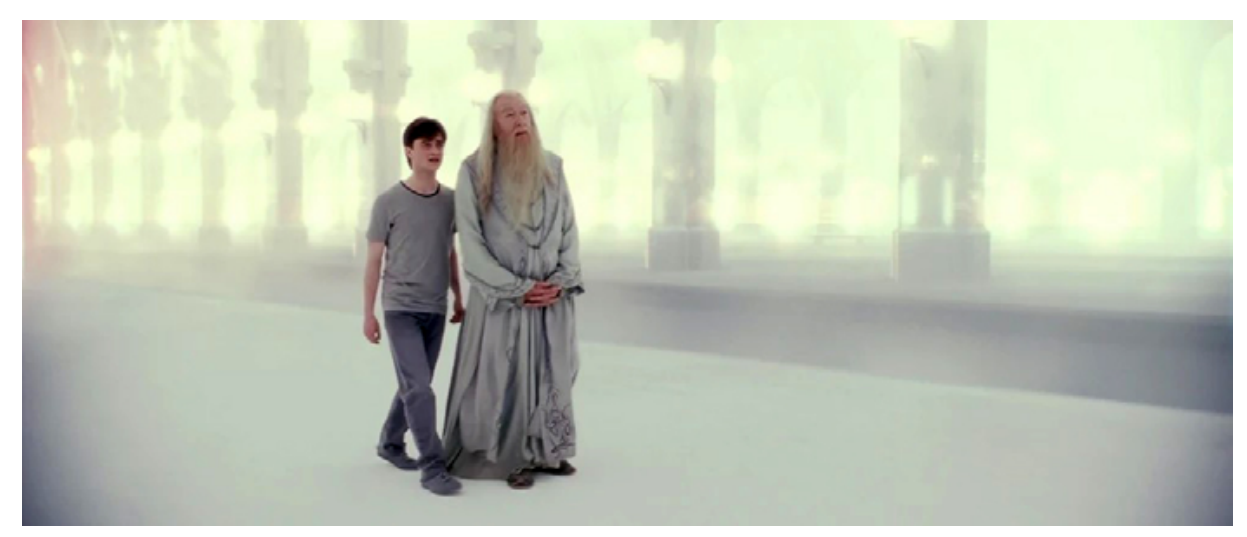

Fig. 6. Harry y Dumbledore en un celestial King's Cross. Fotograma de Harry Potter and the Deathly Hallows - Part 2 (Harry Potter y las Reliquias de la Muerte Pt. 2).

we join the story and see ourselves as part of it: we place ourselves into the story and walk with the characters. In terms of persuasion, we walk in the shoes of the protagonist». Por ello el héroe en su viaje personal no solo se enfrenta al mal, sino que modela su propia identidad y diseña la integridad de su carácter y voluntad. En este sentido, Dumbledore se encuentra a sí mismo (Rowling lo diseña) a través de Gandalf, de Merlín e incluso de Obi Wan Kenobi; mientras Harry lo hace a través de Dorothy Gale, pues en ambos casos exploran un mundo desconocido y hostil que, tras cumplir su misión, les reafirma en la necesidad del retorno, pues... «there is no place like home» -entendiendo hogar como un término ambiguo y reformulable de manera individual, además de como se suele utilizar en gran parte de las narrativas tradicionales sobre el héroe-.

La filiación de Albus con Odín u otras divinidades nórdicas resulta más sutil, pero no por ello nos parece menos intencionada. La propia escritora británica, especialmente tras algunas de las noticias aparecidas en Pottermore, propuso, ante cierto asombro de la legión de fans, la homosexualidad del director de Hogwarts, quien habría mantenido una relación en su juventud con Gellert Grindelwald, otro mago oscuro, en la línea de Voldemort.

Evidentemente Odín, al que se le denomina en ocasiones como el de la larga barba o el de la barba gris, compartiría una iconografía similar a la del mago y, al igual que este, parece tener habilidades psicopompas. El primero guiaba las almas de los caídos en batalla hacia el Valhalla, mientras Dumbledore parece hacer lo propio cuando Harry, en la última de las novelas y películas -Harry Potter y las reliquias de la Muerte-, parece haber muerto, al menos su parte horrocrux, y este lo guía por un limbo etéreo y vacío que recuerda a un King's Cross desmaterializado, cuando ante las dudas del joven le indica: «Creo que si lo deseas puedes abordar de nuevo un tren", antes de que despierte de vuelta a la vida jugando con la sugerente 
idea del retorno/renacimiento. Además, si al primero se lo denomina «el dios de las runas» o Runatyr, Dumbledore posee la capacidad de leerlas y el libro que lega de manera póstuma a Hermione Granger, Los cuentos de Beedle el Bardo, parece estar escrito con ellas.

Pero volvamos a la controversia sobre su orientación sexual. Decíamos unas líneas más arriba que es posible que Rowling se la hubiera replantado a la luz de algunos de sus referentes mitocríticos, que proponen nuevas lecturas partiendo de lo que Gilbert Durand denominaba como «estructuras de lo imaginario». Para nosotros este acercamiento parece sumarse a unos cambios más propios del signo de los tiempos y del peso de la cultura LGBT+ que a otras cuestiones de mayor calado intelectual, pero partiendo del presupuesto anterior son conocidos algunos textos que hablan de la orientación sexual de la divinidad nórdica y con los que pudiera existir algún paralelismo. Según Signe Cohen, que reflexiona sobre premisas similares a las nuestras:

It is occasionally suggested in Norse myths that due to his connection with seidr (magic), Odin may be suspected of being argr. This unique Old Norse term of insult can be transliteration as unmanly, but also carries the connotation of male homosexuality and the unmanly pursuit of magical knowledge (2016).

Por tanto, parece que Rowling, en su búsqueda de referentes para la construcción de sus personajes, encontraría estos de la figura de Odín perfectamente transportables a la de Dumbledore, aunque posteriormente la escritora aportara otros datos afines a la propia hipertextualidad de sus relatos. Este uso de la mitología nórdica podemos rastrearlo también en otros profesores de la escuela, caso de Severus Snape (Cohen 2016).

Las múltiples capas de significantes que encontramos en todas las novelas y, como es natural, en todas las películas de la saga, proponen un protagonista modelado a base de fuentes muy diferentes, combinadas y reunidas en una suerte de bricolaje posmoderno. La diferencia entre Harry Potter y todos los anteriores deriva de la falta de definición de este, pues, aunque evidentemente esté cincelado bajo los parámetros del héroe clásico, es a su vez todos y ninguno de ellos. Cada filme revela diferentes capas de su persona, que salen a la luz en su continuo enfrentamiento con lord Voldemort, así como con el resto de personajes ambiguamente morales con los que parece vincularse en cada uno de los episodios.

Ya apuntábamos con anterioridad cómo Harry se emparentaba con la protagonista de El maravilloso mago de $O z$ (L. Frank Baum 1900), Dorothy Gale, en la necesidad del retorno, en la vuelta a la presunta normalidad tras cumplir lo que de ellos se espera. Es así como sus historias se constituyen en una especie de relato cíclico en el que se vuelve al punto de partida con unos personajes que ya no son ni la sombra de lo que fueron. El crecimiento personal, la transformación y el cambio son constantes en la reelaboración del héroe clásico, pero en el caso del mago, su figura parece estar modelada por un cruce entre el heroísmo de un rey Arturo, la valentía de un san Jorge que se enfrenta al dragón y un Perseo que degüella a la Medusa. 


\section{HARRY POTTER: MAGIA Y CRISTIANISMO}

En un trabajo anterior a este (2020) ya profundizábamos en la clara relación de la figura de Potter con la de Jesucristo. Obras previas, como la de Connie Neal (2007), ya lo habían hecho desde el punto de vista de la relación de este con los relatos evangélicos, en un intento de revelarlos como un proceso de aprendizaje moral en paralelo al de los textos neotestamentarios. Nuestra aproximación derivaba de la consideración de Harry como Mesías, pues recordemos que en las novelas se le denomina "el Elegido», en el sentido de ser el único que podría acabar con lord Voldemort -el Mal-, aunque paradójicamente fuese Neville Longbotton quien finalmente lo hiciera; mientras que Hermione Granger, su inseparable compañera, recuerda en varias ocasiones su innata capacidad para ayudar/salvar a los demás. Es innegable que la autora ve cualidades en su protagonista que todos atribuimos a la figura evangélica: capacidad de sufrimiento, altruismo, humildad, sacrificio, bondad, incluso los episodios de ira del Nazareno - pensemos en la expulsión de los mercaderes del templo- los encontramos también en la figura del mago, como si compartieran incluso sus debilidades. Al margen quedarían las virtudes taumatúrgicas de ambos, que son, sin duda, las más evidentes, y el episodio, ya citado, de la «muerte y resurrección» con su alto valor simbólico, especialmente si, como plantea Cohen (2016), pudiésemos hacer una lectura diferente del lugar en el que esta sucede.

Proponíamos la posibilidad de que ese episodio tuviera lugar en una desmaterializada estación de King's Cross, nombre que obviamente evoca la cruz de Jesús, con lo que la historia de Harry volvería a mostrar un carácter cíclico, comenzando y terminando en esta, «suggesting that his journey is, in one sense, imbued with a Christian allegorical meaning» (Cohen 2016). Cada vez el cruce resulta más evidente, lo que no debería extrañarnos si, como la propia Rowling ha confesado en más de una ocasión, Tolkien fue uno de los referentes más naturales en la conformación de la narrativa de la escritora.

Más arriesgada, a priori, sería su relación con uno de los héroes por antonomasia del cine de ciencia ficción: Luke Skywalker. El protagonista de la trilogía original de Star Wars, recuperado en los últimos filmes de la franquicia, parece antagónico a Potter, pero es evidente que George Lucas lo imaginó con elementos de la sustancia mítica y eterna de la figura del héroe que, obviamente, comparte con Harry, a saber: nacimiento complicado, ausencia de referentes paternos y maternos, lucha constante contra las figuras que representan el mal, atracción por parte del "lado oscuro", altos conceptos morales, fidelidad a prueba de toda duda, capacidad de sacrificio, falta de desfallecimiento, cierta ingenuidad y, por último, ambos acabarán muriendo por salvar a los demás -aunque en Harry sea un estado transitorio, mientras que Luke puede aparecerse más adelante como holograma para convencer a una Rey sumida en un mar de dudas sobre su identidad Jedi-. Quizá todo sea meramente casual, pero no deja de ser absolutamente plausible.

Sin seguir entrando en detalles sobre las múltiples capas utilizadas para modelar al protagonista de la saga, resulta notorio que esta manera de construir el relato trabaja sobre los convencionalismos formales de la literatura posmoderna. Todas las novelas ofrecen esta sensibilidad que juega con la libre yuxtaposición de 
diferentes referentes mitológicos, así como tradiciones religiosas y populares que burlan los convencionalismos tradicionales.

Las escaleras interiores de Hogwarts cambian de orientación, se mueven, los escalones desaparecen e, incluso, algunas de las puertas de la escuela ni siquiera son lo que parecen. Incluso hay espacios que cambian de forma y función, como la Sala de los Menesteres o de los Requerimientos. Pero también Minerva McGonagall se transforma en gato, Peter Pettigrew en rata, Remus Lupin en lobo, o Hermione Granger en Beatrix Lestrange; y todo ello parece una metáfora de la estructura multicapa e indeterminada del relato, un lugar donde todo fluye constantemente interactuando con los protagonistas y borrando los límites de la metaficción dentro del propio relato. Rowling se convierte así en una maestra del juego, de la manipulación y del equívoco.

El mundo mágico de la autora, lleno de resonancias de todo tipo, se orienta así hacia un lector contemporáneo que desconoce las fuentes que maneja, más allá de que pueda identificar las imágenes y las historias más comunes, propias de la tradición cultural y religiosa de Occidente, y transformadas para la ocasión. En él los jóvenes lectores y espectadores de la saga han seguido a un Harry que mientras se busca a sí mismo en realidad lo hace para encontrar su lugar en el mundo, su propia identidad, que resulta surgir en esa alteridad profundamente religiosa del relato. Es así como la búsqueda de lo individual no deja de ser un bucear en la multiplicidad de las narrativas culturales que han ayudado a forjarla.

Dejando de lado la figura del protagonista, hay otras muchas referencias veladas de filiación judeocristiana en las novelas y películas, algunas de ellas ya comentadas anteriormente, mientras que otras más sutiles serán las que analizaremos en las páginas que siguen.

Cuando lord Voldemort fracasa en el intento de asesinar a Harry Potter siendo este apenas recién nacido, queda absolutamente debilitado, incluso pierde su corporeidad y debe esconderse. Lo mismo sucedería con sus seguidores, muchos de ellos perdieron la vida y otros tantos fueron apresados y recluidos en Azkaban, una prisión situada en el mar del Norte, que quedaría oculta para el mundo muggle. Peter Pettigrew fue uno de estos, uno de los más leales junto a los mortífagos, cuya persecución recuerda a la de los primeros cristianos; mientras que los fallecidos serían los mártires de una causa iniciada por Gellert Grindelwald y secundada por Voldemort.

En Animales fantásticos: los crimenes de Grindelwald (Fantastic Beasts: The Crimes of Grindelwald, David Yates, 2018), este arenga a sus seguidores en el cementerio de Père-Lachaise (1:45:20) al respecto. Veamos cómo orienta sus palabras y qué resonancias nos ofrecen:

Hermanos, hermanas, amigos..., el fabuloso obsequio de vuestro aplauso no es para mí, no; es para vosotros. Hoy estáis aquí porque tenéis un anhelo, la certeza de que lo que antes no servía ahora ha dejado de hacerlo. Hoy estáis aquí porque anheláis algo nuevo, algo diferente.

Dicen que odio a los non-magique, a los muggles, a los no-magos, ja los sin magia! (Gritos)

No los odios, noo..., pues yo no peleo movido por el odio. Para mí los muggles no son inferiores, sino diferentes. No valen menos sino que su valor es otro. No son 
inútiles, sino que son útiles para otros menesteres. La magia solo aflora en seres excepcionales. Les está reservada a los que se entregan a propósitos elevados.

Oh, y qué mundo construiríamos para toda la humanidad aquellos que enarbolamos la libertad, la verdad y el amor.

[...] Ha llegado la hora de que comparta mi visión del futuro que nos aguarda si no nos alzamos y ocupamos el lugar que por derecho nos corresponde en el mundo.

Grindelwald cambia brevemente la orientación del discurso para presagiar que la Segunda Guerra Mundial está por venir, y prosigue:

Eso es lo que combatimos. Ese es el enemigo. Su arrogancia, sus ansias de poder, su barbarie. ¿¿Cuánto tardarán en volver sus armas hacia nosotros?! No hagáis nada cuando oigáis esto. Mantened la calma y reprimid vuestras emociones. ¡Hay aurores aquí entre nosotros!

¡Acercaos, hermanos magos, uníos a nosotros!

En ese momento interviene Theseus Scamander para intentar evitarlo:

No hagan eso, no usen la fuerza.

Y termina Grindelwald:

Han matado a muchos de mis seguidores. Es cierto. Me encerraron y torturaron en Nueva York. Acabaron con compañeros magos y brujas por el mero hecho de perseguir la verdad. Por querer la libertad. Vuestra ira, vuestro deseo de venganza es innato.

Inesperadamente muere una de sus seguidoras, que es atacada por un auror y a los pies de la fallecida termina su arenga:

Entregad a esta guerrera a su familia. Desapareced. Marchaos. Salid de aquí y haced que corra la voz. No somos nosotros los violentos.

Este pasaje de la citada película ofrece, como decíamos más arriba, una serie de elementos importantes, a saber: una causa en la que se enarbola la bandera de la paz, de la libertad y del amor; una causa que tiene sus primeros mártires y que termina animando a marchar y expandir la palabra; una causa que difunde la verdad. Si sustraemos estos elementos del discurso parece que estuviésemos ante uno de los Sermones de la Montańa: "Bienaventurados los que trabajen por la Paz...» (Mt 5,9); «Bienaventurados los perseguidos por causa de la justicia...» (Mt 5,10); o «Bienaventurados seréis cuando os injurien, y os persigan y digan con mentira toda clase de mal contra vosotros por mi causa. Alegraos y regocijaos, porque vuestra recompensa será grande...» (Mt 5,11-12). De nuevo se hace evidente la inspiración de Rowling no solo en los relatos neotestamentarios, sino en la propia estructura narrativa de los mismos.

Por otra parte, sus palabras no dejan de mostrar las tesis supremacistas del propio Grindelwald, que a la postre favorecerían el ascenso de lord Voldemort y el 

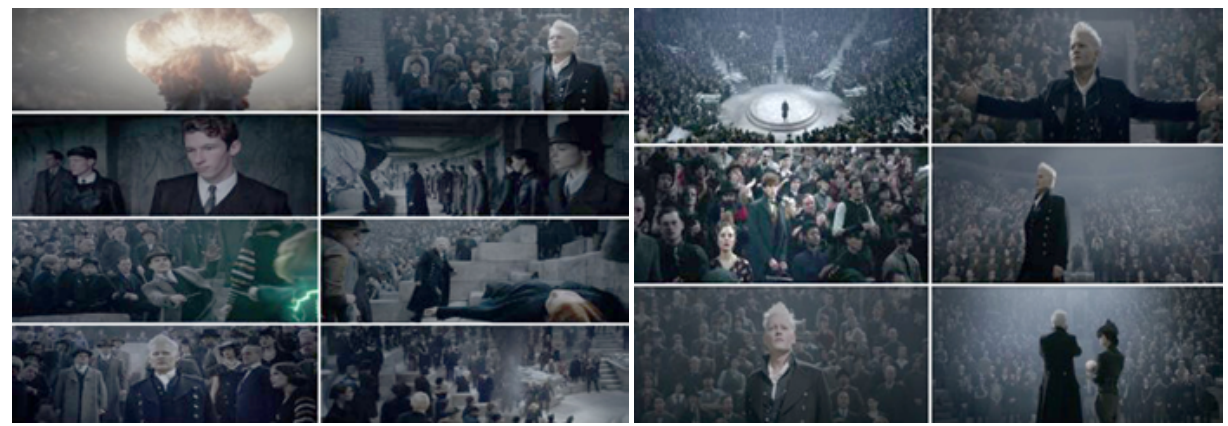

Figs. 7 y 8. Fotogramas de la secuencia anterior. Fantastic Beasts: The Crimes of Grindelwald (Animales fantásticos: los crimenes de Grindelwald).

advenimiento de una nueva edad oscura en el mundo mágico, quintaesencia de las novelas de la saga: la lucha entre el bien y el mal, entre la luz y la oscuridad.

La propia Rowling ofrece a través de la página Wizardingworld datos sobre la infancia de este, cuando aún usaba su nombre, Tom Marvolo Riddle, en la que confirma la supremacía de los magos sobre aquellos que no lo son:

There is some unacknowledged self-disgust in Riddle's Muggle-hatred. He does not deny his half-blood status, but he is clear that Muggles are inferior, including his own father. His viciousness to Muggle-borns is connected: Riddle may be halfblood, but Muggle-borns can claim no wizarding heritage, therefore to him they are as low as Muggles themselves. Riddle also hates Muggles because they remind him of his childhood and the Muggle father who deserted him (n.d.).

Por otra parte, es cierto que en más de una ocasión se la ha criticado por distorsionar conceptos como el bien y el mal, o por no ofrecer un claro posicionamiento de sus personajes ante estas cuestiones, ya que pueden transitar entre una y otra; aunque Nicholas Bury (2000), reverendo decano de Gloucester, que había concedido permiso a la Warner para rodar en su catedral, afirme con rotundidad que «en los libros de Harry Potter la bondad, la honestidad y la integridad vencen a las mentiras y los engaños».

Aun así, las críticas por la ambigüedad moral de la autora han sido constantes, especialmente por parte de los escritores de filiación evangélica, quienes entienden cualquier comportamiento que se desvíe de las enseñanzas bíblicas como una traición a su espíritu. Y si en las primeras obras de la saga esto se podía intuir, en las últimas, en las que la muerte se convierte en el epicentro del relato, todo ello será mucho más evidente. Para la cultura evangélica estadounidense cualquiera de las resoluciones de la autora británica caería dentro de lo que ellos denominan como "ocultismo». El término es tan amplio que a cualquiera de los lectores criados fuera de ella pareciera que han perdido la razón con el listado de prácticas que incluyen y que, por otra parte, para gran parte del resto de la humanidad carecen de cariz reli- 


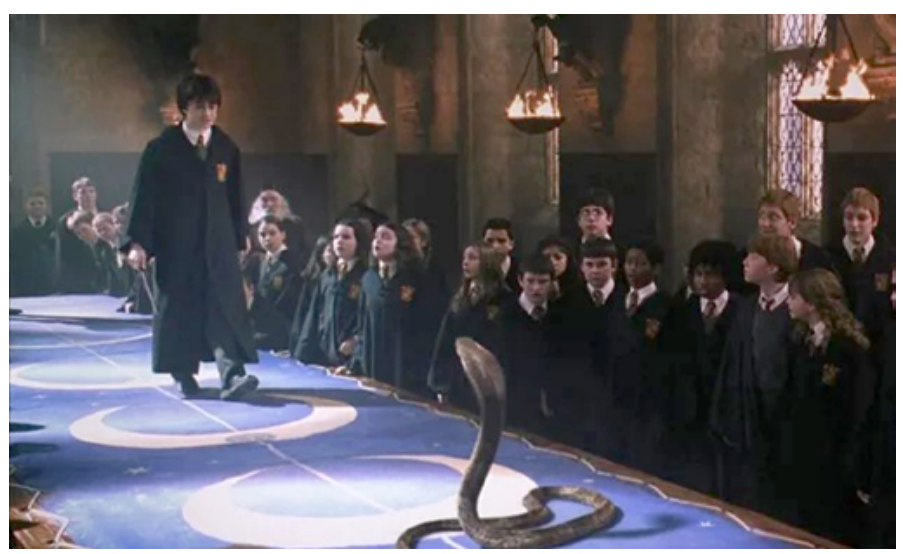

Fig. 9. Harry Potter hablando Parsel. Fotograma de Harry Potter and the Chamber of Secrets (Harry Potter y la cámara de los secretos).

gioso: astrología, interpretación de sueños, adivinación, quiromancia, tarot o telequinesia, entre otras que sí parecen tener cierta conexión, como el chamanismo, el vudú, la hechicería o el satanismo.

Obviamente, esta interpretación será un tema recurrente en las críticas a la escritora, pues hay referencias que dirigen al lector hacia ello. No solo es que Harry pueda hablar con serpientes (lengua pársel) y que estas sean un animal maldito en la Biblia, sino que poseen un carga icónica y simbólica negativa, bastante latente, por otra parte, en la historia del ocultismo. El pársel, además, había sido el don que el joven habría recibido por parte de lord Voldemort -representación, como ya hemos indicado, del Mal- inintencionadamente cuando intentara acabar con él. El principal reproche a estas cuestiones deriva de que Rowling no repara en nada de ello, sino que, según los lectores evangélicos, tienen una consideración más positiva que cualquier concepto de moralidad cristiana que pueda aparecer a lo largo del relato. El problema deriva de valorar estas críticas cuando desde esos mismos foros se tacha de filmes lesivos para los espectadores, por exactamente los mismos motivos, obras tan blancas e inocentes como Ghost, Más allá del amor (Ghost, Jerry Zucker, 1990).

Más interesante resulta analizar cómo estos mismos colectivos, tan intransigentes con la obra de la británica, pues la consideran dramática para la fe, defienden las sagas de Tolkien y de Lewis. Esta valoración deriva del diferente concepto de «magia» con el que trabaja cada uno de estos autores, independientemente de la calidad de las obras de los primeros, muy por encima de las de Rowling.

Para ellos, Tolkien y Lewis vinculan su obra a lo que denominan como «literatura poética mitológica», mientras que la escritora británica hace transcurrir su saga en la sociedad contemporánea, con referencias a acontecimientos de nuestra historia actual. A partir de ese hecho, la lucha entre el bien y el mal en Tolkien deviene de la fe católica del autor, mientras que Rowling se mantiene distanciada 
en la perspectiva espiritual de sus relatos. Por la misma razón, la teología cristiana está presente en los libros de Lewis y no en los de la autora británica.

Por otra parte, si para ella la propia naturaleza del relato depende del poder de la magia y de quien es capaz de controlarla, en ellos no sucede de la misma manera, pues ponen de manifiesto una mayor preocupación por asuntos que podríamos denominar de carácter ético y moral. Por tanto, en Potter la magia es inconstante y voluble, depende de mil posibles variables sin reglas firmes que distingan lo correcto de lo incorrecto, el bien del mal, muy al contrario de las lecciones morales que imparten en sus obras los dos grandes de la literatura de fantasía anglosajona (Abanes 2003), sin tener en cuenta que los tres autores corresponden a generaciones muy separadas en el tiempo, con conceptos sobre la moralidad y la justicia matizados, entre otras muchas cosas, por ello.

Aun así, habría que recordar a sus críticos que muchas de las historias del Antiguo Testamento no son sino un constructo mitológico con varas de medir muy irregulares sobre los mismos conceptos con los que ella trabaja, lo que los hizo ser reelaborados por razones similares en los textos neotestamentarios. Misma oscuridad, misma luz, mismas tinieblas, misma inconstancia.

Para nosotros, la propia esencia de Harry Potter como arquetipo tiene claras concomitancias con la de Jesús: la inocencia perdida, la búsqueda del sentido de la vida, la rebeldía ante el propio destino, la magia como don manifiesto y la lucha como sentido último de la existencia; como si todo ello fueran las diferentes etapas por las que deben (han tenido que) pasar para así llegar al punto culmen de sus historias vitales. Además, en ambos casos, tendremos un enemigo en la sombra que ayuda a entender mejor su sacrificio y el alcance de su epopeya vital, de su mensaje. En la obra de Rowling, Voldemort sería el arquetipo del mal en la sombra mientras que Draco Malfoy será su antagonista, la personificación de su rival.

Es cierto que quizá encontremos otros personajes que representen ese caos del que se quejan los críticos de su obra. Según Julia Ball (2011), los hermanos gemelos Weasley serían un ejemplo de ello:

Fred and George Weasley embody the trickster archetype, representing the acquisition of knowledge in non-tradicional ways, creating chaos in order to destabilise established power structures and delivering keys. The Marauders' Map they presented Harry with not only turns out to be an important clue to Harry's past but also continues to be a central asset throughout the narrative. While the trickster figure is often depicted as two-faced Janus, the Potter series relies on two identical faces, i.e. twins who, somewhat consequently, do not embody god and evil but share the values of the hero. The 'evil' potential of the trickster is reduced to a talent for chaos and a disregard for rules, notably also ascribe to Harry. Both features become significant.

Obviamente, si aceptamos esta lectura sobre Harry y los gemelos Weasley, debemos convenir que en las mismas historias Hermione actúa de manera crucial y ofrece consejos que salvan vidas y que cambian el destino de los protagonistas. Por tanto, las críticas recibidas por este manejo de los potenciales recursos narrati- 
vos carecen de mayor profundidad que una simple pataleta de quienes defienden el cristianismo desde una trinchera integrista bien alejada del signo de los tiempos.

Por otra parte, según Campbell (1993), los héroes deben encontrarse a sí mismos «en el vientre de la ballena», en referencia al relato bíblico de Jonás, quien pasa tres días y tres noches en el interior del animal antes de que el poder divino haga que esta lo devuelva a la vida depositándolo en una playa. Para este autor, la historia del mago describe la necesaria iniciación del protagonista antes de comenzar su aventura, cuando parece haber muerto, para posteriormente renacer y continuar su viaje. Según Ball, Harry vive este proceso con su llegada por primera vez a Hogwarts, un lugar en cambio constante, que hace que metafóricamente muera para el mundo muggle y nazca un nuevo Harry acorde a lo que se espera de él como el elegido, como «the boy who lived».

\section{RECAPITULANDO}

Toda la controversia que hemos expuesto en las páginas que preceden no deja de subrayar cómo la obra de Rowling resulta poliédrica y cómo los diferentes lectores ofrecen reacciones y opiniones muy diferentes ante los mismos acontecimientos. Evidentemente, todo ello dependerá de la formación de cada cual, de sus condicionamientos culturales y de su relación con el mundo. En este sentido, la religión, las creencias, funcionan como un plus que parece dividir a los lectores en dos grupos, los que ven en los relatos potterianos un execrable ejercicio que ahonda en el ocultismo, y los que simplemente ven en ellos una serie de novelas dedicadas a un potencial lector juvenil que se identifica con la figura del joven mago, que forman parte de la literatura contemporánea de fantasía, de la que además toma sus tradicionales patrones narrativos, entre ellos la estructura posmoderna del relato.

La utilización, consciente o no, de referencias cristianas ha permitido realizar diferentes interpretaciones sobre las historias de la saga que, como hemos visto, para el lector de formación evangélica entran en contradicción con los valores y con las enseñanzas bíblicas, especialmente aquellas que tienen que ver con la dicotomía entre el bien y el mal, o con las prácticas relacionadas con el ocultismo, especialmente la magia, contraria a la moral de estos lectores.

Sin duda, la utilización de símbolos cristianos y de fragmentos claramente de inspiración neotestamentaria son evidentes - de hecho, J.K. Rowling confesaría a finales del siglo pasado, cuestionada sobre ello, su profesión de fe-, que son manipulados para adaptarse a los relatos y para que sean fácilmente empatizados por los lectores/espectadores. Es así que gran parte del género de fantasía en el siglo XXI juega con similares referentes y presenta similares virtudes, aunque ello suponga un revival del ocultismo a ojos de los grupos evangélicos, resultado del constante cambio del sentido de las imágenes, así como de las dubitaciones y ejercicios sobrenaturales de los protagonistas de las historias.

Pero Harry Potter va más allá porque no solo ofrece este ámbito de reflexión, sino que, como ejemplo de obra posmoderna, se compone de multitud de capas que permiten, a la vez, repensar el feminismo y el empoderamiento de las mujeres de la 
historia; reflexionar sobre el poder, el sistema de clases y la supremacía racial; hablar de política; de poshumanismo animal, examinar el género y las reglas que lo regulan; estudiar las ideologías en ese mundo de ficción reflejo de la sociedad contemporánea; o hablar de la multiculturalidad. El universo creado por Rowling parece ilimitado en la forma de abordarlo, proliferando la hipertextualidad y la metaficción dentro de los propios relatos.

Sea como fuere, las novelas del joven mago ofrecen múltiples lecturas y acercamientos, lo que permite ser analizadas desde perspectivas muy diferentes, no hay un único patrón que aplicar para su estudio y, por ello, retomando el enfoque de este trabajo y en palabras de K. Frydryszek (2017), «it is remarkable that J.K. Rowling's series do not only provide fantasy elements but also affect morality of people, make people aware through the demonstration of the structure and hierarchy, and induce readers to consideration of some cultural aspects».

Enviado: 4 de marzo de 2021; ACEPTAdo: 30 de abril de 2021 


\section{BIBLIOGRAFÍA}

Biblia de Jerusalén. Bilbao: Desclée de Brouwer.

Abanes, R. (2003). Harry Potter y la Biblia. Madrid: Vida.

Ball, J. (2011). "Harry Potter's Archetypal Journey». Heroism in the Harry Potter Series, Ashgate: Katrin Berndt and Lena Steveker Eds. pp. 85-104.

Bury, N. (2000) «Cathedral Says OK to Harry Potter», Religion News Service, 12 de agosto. Disponible en http://www.religionnews.com. [Consultado 3/02/2020].

Byatt, A.S. (2003). «Harry Potter and the Childish Adult». New York Times, 7 de julio. Disponible en http://www.nytimes/2003/07/07/because-its-his-birthday-harry-potter-by-the-numbers. [Consultado 5-3-2020].

Campbell, J. (1993). The Hero with a Thousand Faces. Londres: Fontana Press.

Conen, S. (2016). "A Postmodern Wizard: The Religious Bricolage of the Harry Potter Series». The Journal of Religion and Popular Culture, Toronto: University Toronto Press, n. ${ }^{\circ} 28: 1$.

Douglas, E.C. (2019). Magic, Monsters and Make-Believe Heroes: How Myth and Religion Shape Fantasy Culture. Berkeley: University of California Press.

Durand, G. (1960). Las estructuras antropológicas de lo imaginario. México DF: Fondo de Cultura Económica.

Frydrysxek, K. (2017). The Bible, Occult, and Harry Potter: Religion in the Fantasy Literature and the Influence of Culture on Perception of the World. Bydgoszcz: Kazimierz Wielki University.

Gaffoglio, L. (2000). «Joanne, Harry Potter y la máquina de inventar». La Nación, 14 de mayo.

Gauvreau Judge, M. (2000), «The Trouble with Harry», Baltimore City Paper, julio. Disponible en http://www.citypaper.com/2000-07012/feature2.htlm. [Consultado 2-3-2020].

Landow, G. (2009). Hipertexto 3.0. La teoría critica y los nuevos medios en una época de globalización. Barcelona: Paidós.

Monteleone, G. (2002). «Harry Potter, un clásico de la posmodernidad». Imaginaria. Revista quincenal sobre literatura infantil y juvenil, Buenos Aires. n. ${ }^{\circ} 74$.

Morris, O. (n.d.). «Elements of the Arthurian tradition in Harry Potter», en Harry Potter for Seekers. Disponible en http://www.harrypotterforseekers.com/ articles/elementsofarthur.php. [Consultado 10-3-2020].

Neal, C. (2007). El evangelio según Harry Potter. Madrid: Ediciones Obelisco.

Robisns, R.A. (2006). «Harry Potter, Ruby Slippers and Merlin: Telling the Client's Story Using the Characters and Paradigm of the Archetypal Hero's Journey». Seattle University Law Review, Seattle: SULR. v. 29. n. ${ }^{\circ} 767$.

Row LInG, J.K. (n.d.). «Analysing Tom Riddle’s choices», en Wizarding World. TM \& (C WBEI. Wizarding World Publishing and Theatrical Stage Rights (C) J.K. Rowling. Disponible en https:// www.wizardingworld.com/features/analysing-tom-riddles-choices. [Consultado 17-3-2020].

SAldaña, A. (2012). «Literatura y Posmodernidad: sobre interactividad y escritura hipertextual». Castilla. Estudios de Literatura. Universidad de Valladolid. n. ${ }^{\circ} 3$. pp. 365-384.

Sola Antequera, D. y Marcos Arteaga, I.C. (2020). «La religiosidad en el relato potteriano: referencias, extrapolaciones e identidades». Actas XXVIII Congreso Internacional Diálogo FeCultura. Santa Cruz de Tenerife: ISTIC. pp. 62-75. 
